Revista de Economia Política, vol. 20, nº 1 (77), pp. 75-82, janeiro-março/2000

\title{
Os Impactos do Euro: uma Avaliação
}

\author{
The impacts of the Euro: an evaluation
}

MÁRIO AUGUSTO BERTELLA*,**

\begin{abstract}
RESUMO: A introdução de uma moeda única (euro), no início de 1999, é um evento histórico no sistema monetário internacional. Este artigo avalia algumas consequências dessa união monetária no mercado de capitais, no desempenho da Europa, na ameaça do euro em relação ao dólar como reserva de valor e possível fonte de instabilidade nos mercados de câmbio.

PALAVRAS-CHAVE: Euro; União Europeia; união monetária; integração econômica; política monetária.

ABSTRACT: The introduction of a single currency (euro), in the beginning of 1999, is a historical event in the international monetary system. This paper evaluates some consequences of this monetary union concerning the capital markets, performance of Europe, the threat of the euro in relation to the US dollar as a store of value and possible source of instability in the exchange markets.

KEYWORDS: Euro; European Union; monetary union; economic integration; monetary policy. JEL Classification: F45; F42; F33.
\end{abstract}

\section{INTRODUÇÃO}

O surgimento da União Monetária e Econômica Europeia (UME), marcado para o começo de 1999, constitui um marco no sistema monetário internacional. A substituição de moedas nacionais, de um número expressivo de economias altamente desenvolvidas de tamanho substancial, por uma única moeda comum não apresenta paralelo na história. Entretanto, enquanto a UME será uma mudança maior, esta união não terá sido abrupta. Quando os líderes dos países membros da União Europeia (UE) decidiram, no primeiro semestre de 1998, quais países participariam desta união monetária desde o seu início, eles estavam dando alguns toques finais a uma cena definida para o terceiro e último estágio da UME, seguindo

\footnotetext{
* Doutorando em Economia pela Universidade Estadual de Campinas - UNICAMP, Campinas/SP, Brasil. E-mail: mabertella@yahoo.com.br.

* O autor agradece aos comentários de Gilberto Tadeu Lima eximindo-o dos erros remanescentes.
} 
o desenho traçado pelo tratado da UE, assinada pelos seus governos em Maastricht em dezembro de 1991. De forma substancial, a realização da UME reflete mais de quarenta anos de estreitamento nos laços econômicos, monetários e políticos dentro da Europa, que se iniciou com o Tratado de Roma de 1957.

A reafirmação do Conselho Europeu em 1988 referente ao compromisso da UE em relação à UME e o Relatório Delors de 1989 definiram o processo em três estágios que conduziriam a UME de acordo com os arranjos do Tratado de Maastricht. O primeiro estágio começou em julho de 1990 e observou a eliminação das restrições remanescentes sobre o movimento internacional de capital por todos os países da UE. O segundo estágio iniciou-se, em janeiro de 1994, com o aparecimento do Instituto Monetário Europeu (embrião do Banco Central Europeu) com a proibição do financiamento monetário de déficits fiscais e do acesso privilegiado do setor público às instituições financeiras e procedimentos para a vigilância de políticas econômicas pelas instituições da UE foram reforçadas. No começo do terceiro estágio, uma moeda comum, o euro, seria introduzida e o Banco Central Europeu assumiria a responsabilidade pela política monetária.

\section{IMPACTOS}

Os efeitos da UME sobre a economia mundial dependerão dos encadeamentos externos sobre o desempenho da Europa e da extensão em que o euro for usado nas transações internacionais. Este último será influenciado pela força e estabilidade da nova moeda, como também do desenvolvimento, no período de transição, das moedas dos membros potenciais da UME.

De maneira ampla, os motivos pelos quais a UME teria consequências importantes e rápidas sobre o sistema internacional incluem, entre outros:

1. A eliminação dos custos de transação com as diversas taxas de câmbio dos países da UME (estima-se uma economia da ordem de US\$ 30 bilhões ao ano) ${ }^{1}$;

2. Uma integração financeira e econômica mais rápida entre os países membros da UE poderá eventualmente criar o maior mercado financeiro de moeda única no mundo;

3. Dadas as dimensões econômicas, financeiras e comerciais, o euro poderá tornar-se uma ameaça ao dólar enquanto moeda reserva;

4. advento do euro poderá representar fonte de instabilidade nos mercados cambiais.

Num período relativamente rápido, vários fatores sugerem um papel mais amplo e, assim, uma maior demanda pelo euro que pelas moedas atuais da UE, que

\footnotetext{
${ }^{1}$ Cf. Salvatore (1998).
} 
são sub-representadas nas transações globais relativas ao dólar, apesar do tamanho similar de suas economias (tabela 1). Embora os EUA e a UE respondam por cerca de $20 \%$ do produto mundial e $15 \%$ das exportações mundiais, perto da metade do fluxo mundial do comércio tem preços em dólar comparado com apenas $30 \%$ das moedas da UE. Os ativos globais, públicos e privados, estão também denominados em dólar de maneira desproporcional, incluindo metade do estoque da dívida dos países em desenvolvimento e $37 \%$ do total dos títulos de dívidas internacionais, comparado com participações ao redor de $16 \%$ e $34 \%$, respectivamente para as moedas da UE. O dólar é de longe usado mais extensivamente que as moedas da UE em reservas oficiais e é a moeda mais frequentemente utilizada nas transações de divisas, estando envolvida em mais de $40 \%$ destas transações, comparado aos $35 \%$ para todas as moedas da UE com transações intra-UE incluídas.

Tabela 1: Tamanho Econômico Relativo e Uso Relativo de Moedas (em percentual)

\begin{tabular}{lccc}
\hline & EUA & Japão & UE15* \\
\hline Tamanho econômico relativo & & & \\
$\quad$ Participação no PIB mundial, 1996 & 20,7 & 8,0 & 20,4 \\
Participação nas exportações mundiais, 1996 & 15,2 & 6,1 & 14,7 \\
\hline Uso relativo de moedas & & & \\
$\quad$ Comércio mundial, 1992 & 48,0 & 5,0 & 31,0 \\
Títulos de dívida externa, 1996 & 37,2 & 17,0 & 34,5 \\
Dívidas de países em desenvolvimento, 1996 & 50,2 & 18,1 & 15,8 \\
Reservas externas, 1995 & 56,4 & 7,1 & 25,8 \\
Transações de divisas, 1995 & 41,5 & 12,0 & 35,0 \\
\hline
\end{tabular}

Fonte: FMI (1997a).

* Alemanha, Áustria, Bélgica, Dinamarca, Espanha, Finlândia, França, Grã-Bretanha, Grécia, Holanda, Irlanda, Itália, Luxemburgo, Portugal e Suécia.

A maior base econômica do euro e a eliminação dos custos de transação envolvidos com múltiplas taxas de câmbio farão aumentar gradualmente a nova moeda europeia como unidade de conta na denominação dos fluxos comerciais, com particular crescimento nas transações entre a área do euro, os países em desenvolvimento e em transição.

Economias de escala no uso do euro induzirão firmas de outras áreas, que comercializam principalmente com a UE, a começar a usar o euro (e.g. Europa central e oriental, Oriente Médio e Norte da África), bem como muitas multinacionais japonesas e norte-americanas. O papel do euro crescerá por sua habilidade em capturar mais o espaço que hoje é ocupado pelo dólar no comércio que não envolvem os EUA. O processo também dependerá da estabilidade das taxas de câmbio entre o dólar, o euro e o yen. Se o dólar apresentar alta volatilidade contra o yen e o euro, enquanto o câmbio entre os dois últimos for relativamente estável, as chances do euro poderão crescer para ocupar um espaço maior no cenário internacional. 
Argumenta-se que as empresas procuram operar com uma moeda que tenha relativamente baixo risco de inflação e de câmbio real (Tavlas, 1997) ${ }^{2}$

A introdução do euro poderá eventualmente criar o maior mercado financeiro de moeda única no mundo. Do ponto de vista de um mercado único, o valor dos títulos da UE e empréstimos bancários circulando nos mercados de capitais europeus totalizava mais de US\$ 27 trilhões no fim de 1995, comparado com 23 e 16 trilhões nos mercados de capitais dos EUA e Japão, respectivamente (tabela 2). Os benefícios potenciais de estabelecer a presença do euro nos mercados de capitais internacionais poderiam ser consideráveis em termos de liquidez e profundidade, como também de reduzir os custos para os tomadores de empréstimos. A partir do momento que o euro for introduzido, os emprestadores e tomadores de recursos começarão a procurar retornos mais altos e custos mais baixos através das fronteiras nacionais. Os mercados financeiros europeus podem tornar-se menos segmentados e poderia haver maior uniformidade nas práticas de mercado e transparência nos preços de ativos (FMI, 1997b).

Tabela 2: Indicadores do Tamanho dos Mercados de Capitais, 1995 (em bilhões de dólares)

\begin{tabular}{lcccccc}
\hline & PIB & $\begin{array}{c}\text { Reservas } \\
\text { Totais } \\
\text { Menos Ouro }\end{array}$ & $\begin{array}{c}\text { Capitalização } \\
\text { Mercado } \\
\text { Açóes } \\
\text { (A) }\end{array}$ & $\begin{array}{c}\text { Títulos de } \\
\text { Dívida* } \\
\text { (B) }\end{array}$ & $\begin{array}{c}\text { Ativos } \\
\text { Bancários } \\
\text { (C) }\end{array}$ & A+B+C \\
\hline UE15 & $8.427,6$ & 376,3 & $3.778,5$ & $8.673,4$ & $14.818,0$ & $27.269,9$ \\
Estados Unidos & $7.253,8$ & 74,8 & $6.857,6$ & $11.050,6$ & $5.000,0$ & $22.908,2$ \\
Japão & $5.134,3$ & 183,3 & $3.667,3$ & $5.324,8$ & $7.382,2$ & $16.374,3$ \\
\hline
\end{tabular}

Fonte: FMI (1997b).

* Títulos ("securities") de dívidas pública e privada, interna e externa.

Segundo o mesmo relatório (FMI, 1997b), mudanças estruturais são necessárias para esta transformação. $\mathrm{O}$ desenvolvimento de mercados de títulos privados de forma ampla na Europa tem sido dificultado, entre outros motivos, por regulamentações nas emissões, negociações e comercialização de títulos, por diferenças nas práticas de mercado e sistemas de compensação. Algum progresso tem sido feito para harmonizar as regulações na emissão de títulos, na supervisão de fundos mútuos de investimento e companhias de seguro e na liberalização dos serviços financeiros, mas ainda, conforme observa o mesmo relatório, requer-se a remoção de vários impedimentos e harmonização de procedimentos de forma a acelerar a integração dos mercados financeiros europeus. De acordo com McCauley \& White (1997), os custos de transação do mercado financeiro em euro a serem reduzidos dependerão, entre outros, dos efeitos de uma maior concorrência bancária proveniente da unificação monetária e da redução dos custos de banking na UE.

${ }^{2}$ Cit. in Portes and Rey (1998). 
Provavelmente, o euro também poderá começar a rivalizar com o dólar enquanto moeda reserva, em parte por objetivos de intervenção e, também, porque seu uso de maneira extensivo e uma maior profundidade dos mercados dos ativos financeiros denominados em euro, comparado com a multiplicidade de moedas europeias atualmente, criará condições para os países diversificarem suas reservas, conforme a composição de suas transações comerciais e financeiras; isto será particularmente importante para os países em desenvolvimento que hoje possuem reservas largamente denominadas em dólares. Deve-se observar também que os países que aderirem a UME poderão ter suas reservas em dólares reduzidas, na medida em que o comercio Intra-UE não mais precisará do suporte de reservas Internacionais. Contudo, como observa Mundell (1993), a história nos ensina que leva tempo para uma moeda reserva mudar. ${ }^{3}$

Outra questão a ser levantada refere-se ao impacto do euro no sistema internacional enquanto fonte de maior instabilidade nos mercados de câmbio. Três argumentos sugerem maior instabilidade. Na medida em que o dólar atua como líder de mercado nos mercados cambiais, o aparecimento de uma moeda como o euro poderá criar uma situação de barganha entre parceiros mais iguais e, assim, provocar maior volatilidade (Wyplosz, 1997). Outro fator refere-se à criação de uma zona do euro que se encontraria com os EUA e o Japão como economias poderosas menos inclinadas em abandonar os objetivos de política doméstica em favor da coordenação de taxas de câmbio (idem). Outro ponto que corrobora a tese de maior volatilidade concerne aos ciclos econômicos. Estes têm se tornado, de maneira ampla, mais similar entre os países da UE nos anos recentes e a integração financeira e comercial sob a UME é provável que aumente a importância de fatores comuns entre os países da UE. Porém, as flutuações cíclicas parecem não ter se tornado mais sincronizadas entre a UE e as economias mais avançadas fora da Europa. Diferenças nas condições econômicas resultantes de choques assimétricos ou de ciclos econômicos não sincronizados e posturas de política divergentes entre as economias mais avançadas (UE, EUA e Japão) poderão refletir-se em flutuações cambiais relativamente pronunciadas. Todavia, a visão oposta é que a mudança do G-7 para G-3 poderia criar condições de mais fácil negociabilidade para a diminuição da volatilidade nas taxas de câmbio (Goodhart, 1993) ${ }^{4}$. Neste sentido, a incerteza inevitável que se segue à introdução da nova moeda e a possibilidade de grandes oscilações entre as principais taxas de câmbio (dólar, euro e yen) pode levar a uma maior cooperação entre os principais Bancos Centrais de forma a reduzir o grau de instabilidade na economia mundial.

De acordo com Salvatore (1998), o impacto do euro sobre o desempenho da Europa, em particular sobre o emprego e a competitividade internacional num prazo mais longo, parece positivo. Um mercado único com uma única moeda tornaria os países da UE mais competitivos globalmente e isto se refletiria numa menor

\footnotetext{
${ }^{3}$ Cit. in Wyplosz (1997).

${ }^{4}$ Cit. in Wyplosz (1997).
} 
taxa de desemprego, embora a expectativa imediata de uma competição mais intensa, quando o euro chegar, estaria induzindo as companhias a cortarem custos e, sempre que possível, também o emprego para se tornarem mais competitivas internacionalmente ${ }^{5}$. Por outro lado, na visão de Feldstein (1997), a mudança para uma moeda única exacerba o desemprego por eliminar a possibilidade de o país praticar políticas monetária e cambial. Uma nação que é parte de uma união monetária deve ter a mesma taxa de juros e a mesma taxa de câmbio que os outros membros da união monetária; a taxa de juros e o valor da moeda somente podem se ajustar na medida em que outras economias da união monetária também experimentarem um mesmo choque. Um país que faça parte de uma união monetária não tem condições de usar políticas discricionárias para aumentar o nível de emprego da nação.

Desta maneira, um sério problema que o estabelecimento de um Banco Central Europeu (BCE) e o euro podem criar é como um membro da UE poderá reagir a um choque assimétrico. E praticamente inevitável que, neste caso, as várias nações que compõem a UE sejam afetadas diferentemente. Assim, o país afetado negativamente pouco pode fazer. E claro que ele não poderá mudar a taxa cambial ou usar a política monetária para superar este problema e a disciplina fiscal imposta também impedirá uma solução mais imediata (Salvatore, 1998).

Ainda o mesmo autor ressalta que o euro poderá criar sérios problemas para regiões e nações periféricas da UE. A maior integração econômica e financeira com o euro poderá aumentar a concentração geográfica das atividades econômicas em áreas centrais da UE e levar a um aumento das desigualdades económicas entre o centro e a periferia. Em outros termos, as áreas e países periféricos provavelmente poderão perder as pessoas mais bem treinadas atraídas por melhores salários e oportunidades no centro da UE. De maneira similar, as poupanças das áreas mais atrasadas poderão direcionar-se para as regiões mais centrais atraídas por menores riscos e maiores retornos. Finalmente, é difícil para indústrias da periferia competirem efetivamente com indústrias dos países centrais (Salvatore, 1998).

Enquanto grandes economias, os EUA e o Japão não serão afetados profundamente por qualquer alteração na variabilidade do euro, embora o equilíbrio comercial bilateral com os países da UME dependerá das taxas de câmbio do dólar e do yen via-à-vis do euro. Efeitos adicionais sobre esses países ocorreriam a partir de um uso mais extenso do euro enquanto moeda reserva e denominador comum para transações de comércio e finanças. Mais concretamente, uma mudança em direção ao euro como reserva de valor reduziria os ganhos de senhoriagem dos EUA. Potencialmente mais importante contudo, é que o desejo de estrangeiros possuírem ativos denominados em dólar torna mais fácil para os EUA financiarem seu déficit do balanço de pagamentos; episódios em que até mesmo um sinal de venda de títu10s do Tesouro por investidores estrangeiros resultando em elevações

\footnotetext{
${ }^{5} \mathrm{O}$ autor ressalva que é a globalização que requer das nações e empresas a promoção de reestruturações, mas o Tratado de Maastricht e o euro têm acelerado este processo.
} 
acentuadas nas taxas de juros norte-americanas de longo prazo, claramente mostram o benefício aos EUA derivado da larga aceitação do dólar.

Movimentos nos valores das principais moedas e o grau de variabilidade da taxa cambial do euro afetará os países em desenvolvimento e em transição com laços econômicos com os países da UME. Possivelmente, os maiores efeitos serão sentidos na Europa central, oriental e nas ex-colônias francesas da África, em parte porque possuem estreitas ligações comerciais com a UE, e em parte porque atrelam suas moedas domésticas ao franco francês ou ao marco alemão (e no futuro ao euro), embora possuam obrigações financeiras denominadas em dólar ou yen (FMI, 1997a). Com tal combinação de moedas, uma desvalorização do euro levaria a um aumento do custo do serviço da dívida em moeda local, provavelmente sem uma total compensação na conta comercial (idem).

Em relação à economia brasileira, os efeitos do euro dependerão da relação entre as duas moedas. Além disso, o processo de unificação europeia poderá refletir-se na questão dos limites da política fiscal. Como se sabe, conforme o Tratado de Maastricht, o déficit fiscal deve ser sustentável e não superior a 3\% do PIB. O mesmo deve ocorrer com a dívida pública bruta que não pode superar $60 \%$ do PIB. Desvios em relação a esses critérios são aceitos, desde que se demonstre que o país em questão está adotando medidas que, sem sombra de dúvidas, impliquem a progressiva redução do déficit e da dívida. Com o déficit público ao redor de $8 \%$ do PIB em 1998, o sucesso do euro poderá repercutir favoravelmente na construção de uma política fiscal mais equilibrada e eficaz.

\section{CONCLUSÃO}

Em resumo, a criação da UME representa um dos mais importantes desenvolvimentos no sistema monetário internacional pós-Bretton Woods. Com o estabelecimento da UME, o euro se tornará a segunda mais importante moeda reserva no mundo e o futuro Banco Central Europeu (BCE) assumirá seu lugar como instituição supranacional a gerenciar uma moeda "multiestatal". Embora os desafios políticos, culturais e econômicos sejam formidáveis, o euro tem o potencial de remodelar o mercado financeiro internacional e transformar o sistema monetário internacional em um sistema tri ou bipolar. No mínimo, o euro provavelmente assumirá um papel significativo no comércio internacional, nas transações financeiras privadas e nas reservas oficiais. Se o euro será inicialmente fraco ou forte dependerá, em grande medida, da administração macroeconômica efetiva e da credibilidade do BCE, como também da habilidade do euro em catalizar as iniciativas existentes em aumentar a eficiência e eficácia do mercado de capitais europeu. 


\section{REFERÊNCIAS}

FELDSTEIN, M. (1997) "The Political Economy of the European Economic and Monetary Union: Political Sources of an Economic Liability”, Journal of Economic Perspectives, vol. 11, 4.

FMI (1997a) World Economic Outlook, Washington, DC, oct.

(1997b) International Capital Markets: Developments, Prospects, and Key Policy Issues, Washington, DC, nov.

McCAULEY, R. \& WHITE, W. (1997) “The Euro and European Financial Markets”, Working Papers, 41, BIS

PORTES, R. \& REY, H. (1998) “The Emergence of the Euro as an International Currency”, Economic Policy, April.

SALVATORE, D. (1998) “Europe's Structural and Competitiveness Problems and the Euro"The World Economy, vol. 21, 2.

WYPLOSZ, C. (1997) "EMU: Why and How it Might Happen”, Journal of Economic Perspectives, vol. 11, 4.Revista de Economia Política, vol. 20, n o 1 (77), janeiro-marco/2000 